\title{
Gestão de projeto interdisciplinar: smart design, design de interação, materialização e projeto de alta complexidade
}

\author{
Management Interdisciplinary Project: Smart Design, Interaction Design, materialization and \\ High Complexity Project
}

\author{
Ana Veronica Pazmino \\ UFSC, Brasil \\ ana.veronica@ufsc.br \\ Rodrigo Braga \\ UFSC, Brasil \\ rodrigo.braga.ufsc@gmail.com
}

Regiane Pupo

UFSC, Brasil

regipupo@gmail.com

\begin{abstract}
This paper presents the management of interdisciplinary practice in design course at the Federal University of Santa Catarina in the design discipline with emphasis on interaction and technology. The work shows the project management used to facilitate the interrelation of design disciplines interaction, intelligent design and materialization through which the students developed an interactive product with the appropriation and application of programming knowledge with arduino, digital manufacturing and interaction. The results are qualitative in relation to students' learning and recommendations for an interdisciplinary design process in design courses.
\end{abstract}

Keywords: project management; interdisciplinarity; Intelligent Design; Interaction; Digital Manufacturing.

\section{Introdução}

O processo de ensino e aprendizagem no âmbito universitário exige que os professores realizem práticas de interconexão entre diversos saberes. Este artigo mostra a gestão do projeto de uma ação pedagógica interdisciplinar, e os resultados da prática projetual. Para isto o trabalho apresenta como objetivo geral, aplicar a gestão do projeto numa ação interdisciplinar como meio para organizar e controlar o processo projetual de alta complexidade. Os objetivos específicos foram:

- Reconhecer os outputs de ação interdisciplinar anterior Pazmino, Pupo, Braga (2014);

- Desenvolver a gestão do projeto;

- Inter-Relacionar saberes de programação,

materialização, interação e design na disciplina de projeto de produto;

- Trabalhar com visão interdisciplinar ao longo do processo projetual;

- Produzir modelo iterativo;

- Validar a gestão de projeto

A partir dos resultados da ação interdisciplinar de 2014, das aulas teóricas e práticas e dos produtos interativos desenvolvidos pelos alunos foi percebida a necessidade de uma gestão do processo de projeto de forma que tanto os professores como os alunos tenham clareza dos cruzamentos e da síntese das quatro disciplinas, instaurando um novo nível do discurso, caracterizados por uma nova linguagem descritiva e novas relações estruturais. A relação de reciprocidade, o regime de co-propriedade, que possibilite o diálogo entre professores e alunos (ação interdisciplinar). Propor a gestão do projeto é o reconhecimento da interdependência de todos os aspectos de cada disciplina do projeto. Obter a consequência normal da síntese dialética provocada pela interdisciplinaridade, quando esta for bemsucedida. (ação transdisciplinar). O trabalho mostra a importância da gestão de uma ação interdisciplinar com três professores de áreas diversas de conhecimento e quatro disciplinas.

\section{Desenvolvimento da gestão}

A disciplina de Projeto 16 é estruturada como mostra a Figura 1.

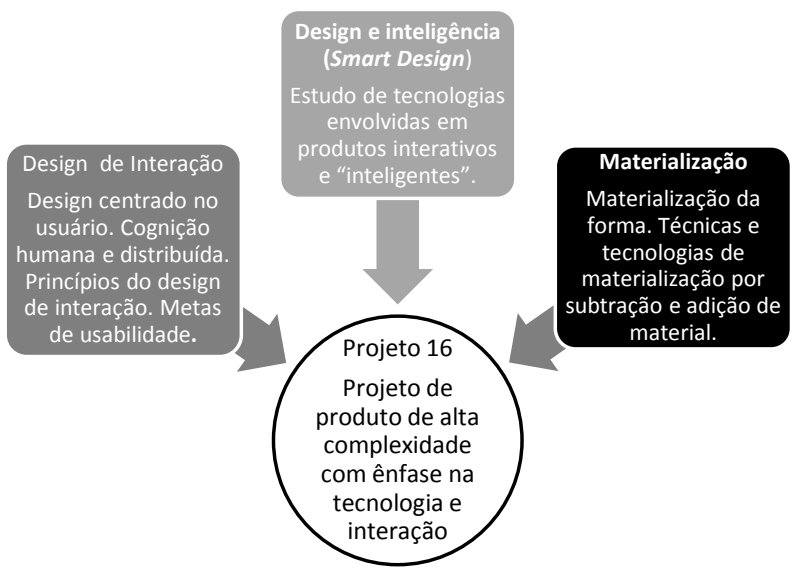

Figura 1 Estrutura da Disciplina de Projeto 16 e suas disciplinas Fonte: do autor, com base na pesquisa realizada 
A partir da estruturação da disciplina foram estabelecidos vários métodos para alcançar os objetivos específicos. A seguir são mostrados os métodos trabalhados.

1. Sintetizar saberes de programação, materialização, interação e de projeto de produto. Os planos de ensino das quatro disciplinas dos três professores envolvidos foram estruturados de forma que os 18 encontros durante o semestre tivessem conteúdos que permitissem as conexões das disciplinas;

2. Estruturar um modelo de gestão do projeto com seus inputs e outputs;

3. Organizar a materialização digital de modelos ao longo do processo projetual.

4. Aplicar conhecimentos de programação. Aulas práticas de tecnologias que permitam a interação (robótica, programação, automação).

5. Produzir modelo interativo de alta complexidade. Aulas práticas de construção de protótipos funcionais $\mathrm{e}$ programação.

Os resultados alcançados envolvem: um modelo de gestão de ações interdisciplinares que pode ser replicado em projetos que envolvam tecnologia, também é mostrada a ação projetual de um produto interativo mostrando a gestão feita com os alunos da disciplina.

\section{Gestão de projeto}

O gerenciamento de projetos é a aplicação de conhecimentos, habilidades e técnicas para a execução de projetos de forma efetiva e eficaz. Trata-se de uma competência estratégica, permitindo com que elas unam os resultados dos projetos com os objetivos previamente estabelecidos.

Segundo Kerzner (2002), a gestão de projetos pode ser definida como o planejamento, a programação e o controle de uma série de tarefas integradas para alcançar seus objetivos com êxito, beneficiando os que participam do projeto. A gestão do projeto envolve cumprir os prazos e acompanhar as ações ao longo do projeto.

\section{Gerenciamento de projeto do PMBOK}

Conforme o PMBOK pode-se dividir o gerenciamento de projetos em nove etapas. A primeira delas é o Gerenciamento da Integração do Projeto. Pelo fato dos projetos de design possuir diversas fases, dependendo dos processos utilizados e dos setores econômicos nos quais são desenvolvidas as soluções, se faz necessária a coordenação e unificação de todas as atividades do projeto. O Gerenciamento da Integração do Projeto abrange todas as ações que permitem identificar e combinar as diversas atividades presentes no gerenciamento de um determinado projeto [PMBOK, 2004].

O Guia PMBOK, divide em etapas cada fase.

São elas:

\section{Gerenciamento de integração}

Faz parte da fase de iniciação, e neste gerenciamento temse uma visão geral da dificuldade do projeto, geralmente identificada na comparação com registro histórico de projetos já executados. Saber que método, ferramenta e equipe deve ser disponibilizada para execução da tarefa. Considerar as restrições do projeto, e criar premissas quando for preciso.

\section{Gerenciamento de escopo}

Formalização de documento com os processos de execução de projeto que deve ser enviado ao cliente e assinado pelas partes, estabelecendo consequências rígidas para o não cumprimento do acordo. (PMBOK, 2004) apud Dischinger et al. (2010) a importância do Gerenciamento do Escopo do Projeto está na identificação dos processos que garantem a execução do trabalho necessário para concluir o projeto com sucesso.

\section{Gerenciamento de cronograma:}

Listar as atividades de forma minuciosa e estimar o tempo de trabalho para cada uma delas. É importante salientar casos de dependência entre as atividades, onde a negligência no cumprimento de uma delas impede de dar sequência ao projeto. Este gerenciamento serve para cumprir e expor o método de trabalho, manter o cliente seguro do andamento, e a equipe de projeto organizada.

\section{Gerenciamento de Custos:}

Expor o método de trabalho e elaborar o cronograma contribui para a elaboração de um orçamento justo, de modo a enfatizar o valor que o conhecimento na área de design tem, o poder de retorno do investimento feito pelo cliente e o custo em relação ao tempo do designer dedicado ao trabalho.

\section{Gerenciamento da Qualidade}

Gerar parâmetros de qualidade, a partir do portfólio. Daí a importância de dar a cada projeto o resultado sempre adequado a sua função e não moldá-lo conforme o gosto do cliente ou do designer.

\section{Gerenciamento de Pessoal do Projeto}

Que inclui os processos que organizam e gerenciam as equipes de projeto.

\section{Gerenciamento das Comunicações do Projeto}

Nos projetos de design, uma das tarefas mais importantes é a coleta dos dados, normalmente iniciada, segundo Pazmino (2015), durante a reunião do designer e o cliente na confecção do briefing. Etapa fundamental para o desenvolvimento de trabalho, o briefing é fruto de uma reunião entre o designer ou equipe de design e seu cliente. Este documento deve ser construído por ambos e deve contemplar todas as informações relevantes do projeto. O briefing deve responder qual será o objetivo do projeto, descrever os problemas que indicam a necessidade do projeto e os possíveis benefícios com a sua implantação. Segundo (PMBOK, 2004) apud Dischinger et a.l (2010), o Gerenciamento das Comunicações do Projeto é a área que emprega os conhecimentos necessários para garantir a geração, coleta, distribuição, armazenamento, recuperação e 
destinação final das informações sobre o projeto de forma oportuna e adequada.

\section{Gerenciamento dos Riscos do Projeto}

Que inclui estratégias para atenuar os riscos naturais que os projetos incluem. Segundo a descrição do PMBOK (2004), o gerenciamento de risco contempla os processos que tratam da realização de identificação, análise, respostas, monitoramento, controle e planejamento do controle de riscos em um projeto; a maioria desses processos sendo atualizada durante todo o projeto.

\section{Gerenciamento das Aquisições do Projeto}

Considera ou não a implementação física do desenvolvimento, os riscos de uma execução equivocada ou distorcida podem existir. Para prevenir que isso ocorra, o ideal, seria o acompanhamento durante todo o processo pelo designer que projetou a solução e pelo cliente. Já que a contratação dos fornecedores para a execução dos serviços é normalmente feita pelo próprio contratante, fica claro que sem que haja uma supervisão não é possível garantir que o que foi projetado, neste caso, será entregue. O Gerenciamento das Aquisições do Projeto inclui os processos para comprar ou adquirir produtos, terceirizar serviços ou resultados necessários de fora da equipe do projeto para a realização do mesmo.

\section{Modelo iterativo de gestão de projeto}

O modelo iterativo atende as nove etapas do PMBOK adaptadas a um projeto acadêmico que inter-relaciona quatro disciplinas, três professores e uma turma de alunos.

Primeiramente serão detalhadas as etapas do projeto e posteriormente será mostrado o modelo de gestão iterativo que permitiu que o projeto fosse desenvolvido dentro do prazo previamente estabelecido.

O Projeto 16 de 2015/2 teve como tema a loT (Internet of Things), Internet das coisas. De acordo com o Cisco Internet Business Solutions Group (IBSG), a loT é o momento exato em que foram conectados à Internet mais "coisas ou objetos" do que pessoas.

O objeto a ser desenvolvido tratou da criação de um produto pet, destinado ao bem-estar dos animais de estimação, e que por meio do auxílio da internet e da tecnologia, devia permitir à distância, um melhor cuidado dos animais.

Considerando que o desenvolvimento com tecnologia e interação é um projeto de alta complexidade, foi adotado o método conhecido como Espiral de Projeto que é amplamente usado em projetos de alta complexidade e com equipes multidisciplinares, pois possuem sistemas complexos com alto grau de interdependência em que é difícil calcular os fatores simultaneamente. Desta forma, as etapas de desenvolvimento são divididas em grupos dispostos de forma espiral, sendo que em que cada volta o desenvolvimento é revisado e aprofundado.

A figura 2 mostra o modelo de gestão em espiral que relaciona as disciplinas envolvidas, o processo projetual, e as 18 etapas realizadas ao longo de 72 horas do Projeto 16. Deve-se salientar que ao longo do projeto os professores e alunos estão compartilhando conhecimentos em uma ação iterativa de análise, teste e materialização.

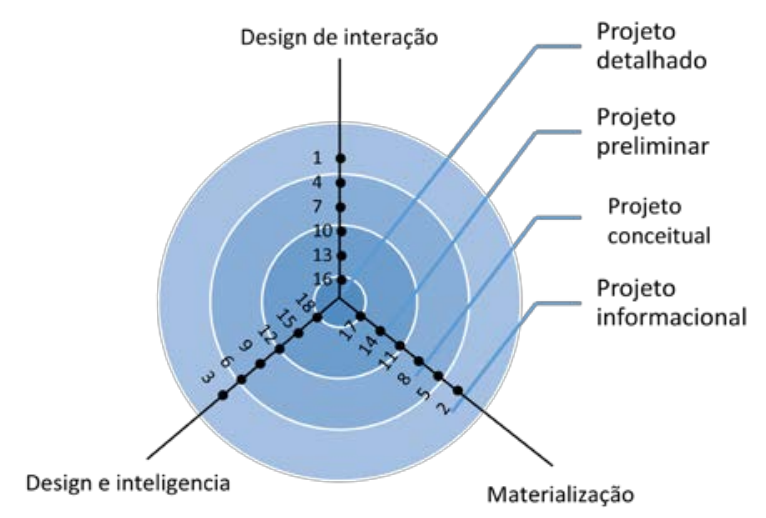

Figura 2 Espiral do Projeto 16.

Fonte: do autor, com base na pesquisa realizada

Segundo Rozenfeld et al. (2006), o desenvolvimento é dividido em quatro fases, a seguir a descrição relacionada ao produto pet:

Projeto informacional - Define o objetivo do projeto Pet. As pesquisas de mercado, definição de público alvo e define a lista de requisitos (tecnológicos e de design) em ordem decrescente de importância.

Projeto conceitual - Esta fase determina se o produto Pet no projeto informacional é factível e se os requisitos terão de ser modificados para que se consiga projetar o produto com sucesso. É a parte mais criativa do processo de forma que a equipe de projeto não limite a criatividade, tentando gerar alternativas que apenas cumpram os requisitos.

Projeto Preliminar - Esta fase determina os detalhes tecnológicos e de design do produto Pet e de como serão alcançados tecnicamente as soluções do projeto conceitual.

Projeto Detalhado - Esta fase é relativa à produção documentos do projeto. Nesta fase serão feitos os desenhos finais do produto pet, desenhos de construção e especificações técnicas. O quadro 1 mostra as etapas realizadas no projeto.

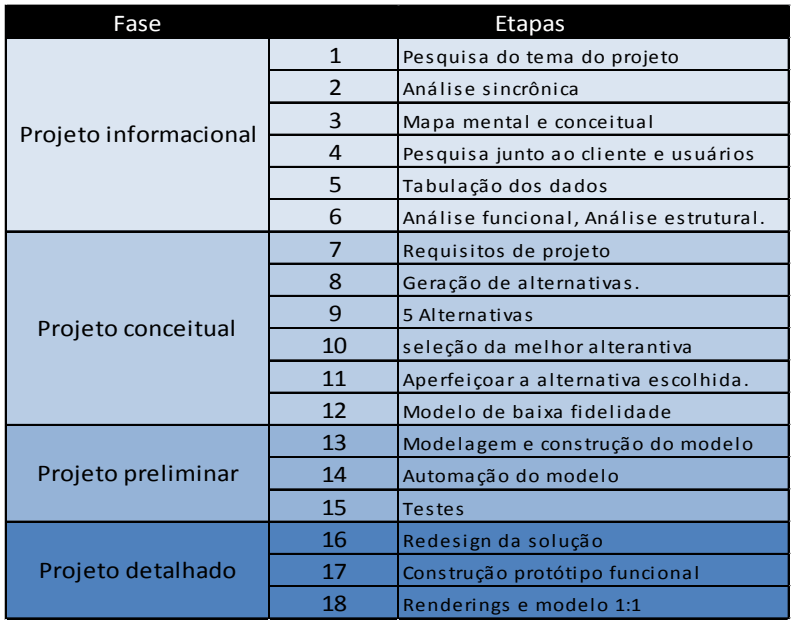

Quadro 1 Etapas do Projeto 16 
Fonte: do autor, com base na pesquisa realizada

A seguir serão detalhadas algumas etapas do projeto e apresentados os resultados.

\section{Etapa 2: Análise Sincrônica}

Para a análise de produtos similares, foi realizada uma pesquisa internet para identificar o que o mercado está oferecendo para solucionar problemas de monitoramento e alimentação de um cachorro em casa ou no apartamento.

Observou-se a gama de produtos oferecidos para monitorar os animais, servir alimento e também os que oferecem divertimento. Entre os produtos analisados, todos possuíam algo interessante e aproveitável, como a tecnologia, as funções, os mecanismos, entre outros.

A Figura 3 mostra o produto com melhores características e no qual foi feita uma lista de verificação para identificar os pontos positivos e negativos.

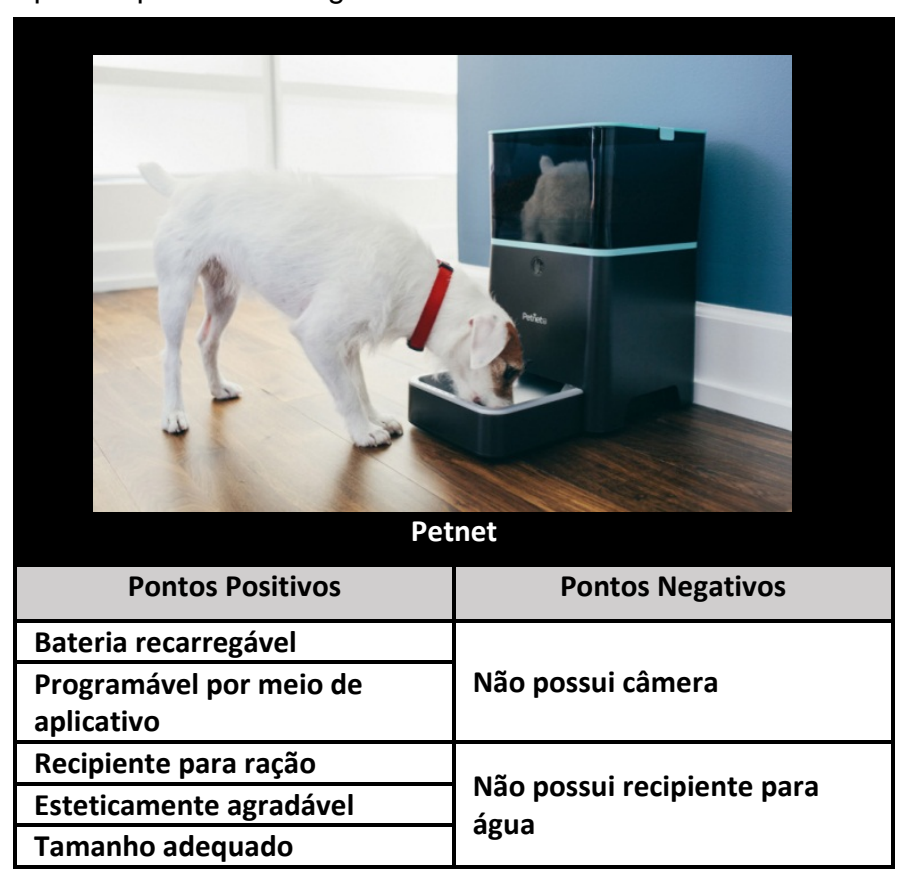

Figura 3 Lista de verificação

Fonte: Cândido et al. (2015)

\section{Etapa 4: Pesquisa com os usuários}

Foram aplicados dois questionários ao público para extrair informações sobre suas rotinas e seus animais de estimação.

O primeiro questionário foi aplicado ao público em geral. A parte inicial do questionário servia para obter algumas informações pessoais, como idade, quais tipos de residência habitam e sobre suas rotinas em relação aos seus animais. $E$ depois contava com perguntas sobre os seus animais de estimação - quantidade de animais que possuem qual o porte deles, como se alimentam, se costuma receber petiscos, para assim, traçar os perfis dos animais e dos seus donos. O questionário conduziu as perguntas de modo a coletar informações sobre a quantidade de pessoas que trabalham ou estudam, que passam praticamente o dia fora de casa e como isso afeta na relação delas com os seus animais de estimação.

Os resultados da pesquisa mostraram que a maioria das pessoas possui grande preocupação com o bem estar dos seus animais, em relação à alimentação e à segurança. Elas sentem falta de serviços que permitam cuidar do animal quando precisam passar longos períodos fora de casa.

Ainda neste questionário, foram perguntadas, às pessoas que não possuíam animais de estimação, as razões por não possuir. Muitas responderam que não possuem animais, pois passam muito tempo fora de casa e não teriam como dar atenção necessária, e assim garantir que estejam bem enquanto ficam sozinhos.

$\mathrm{Na}$ segunda etapa da pesquisa, foi confeccionado outro questionário direcionado ao público-alvo, definido após a aplicação do primeiro questionário. A segunda etapa foi determinante para apontar as características e funções essenciais para o produto. As pessoas entrevistadas classificaram o que para elas era mais ou menos importante em um produto destinado ao cuidado do animal à distância, e definiu-se que o produto deve: Servir água e comida; monitorar o animal e oferecer atendimento de emergência.

Foram realizadas a análise funcional e estrutural e posteriormente se deu início a Etapa 7: Requisitos de projeto. Os requisitos foram classificados em obrigatórios e desejáveis. Alguns como a tecnologia, que deve permitir a interação do usuário com o produto através da internet. $O$ Arduíno como sistema programável para realizar as funções mecânicas para o funcionamento do produto. O Quadro 2 mostra os requisitos do projeto

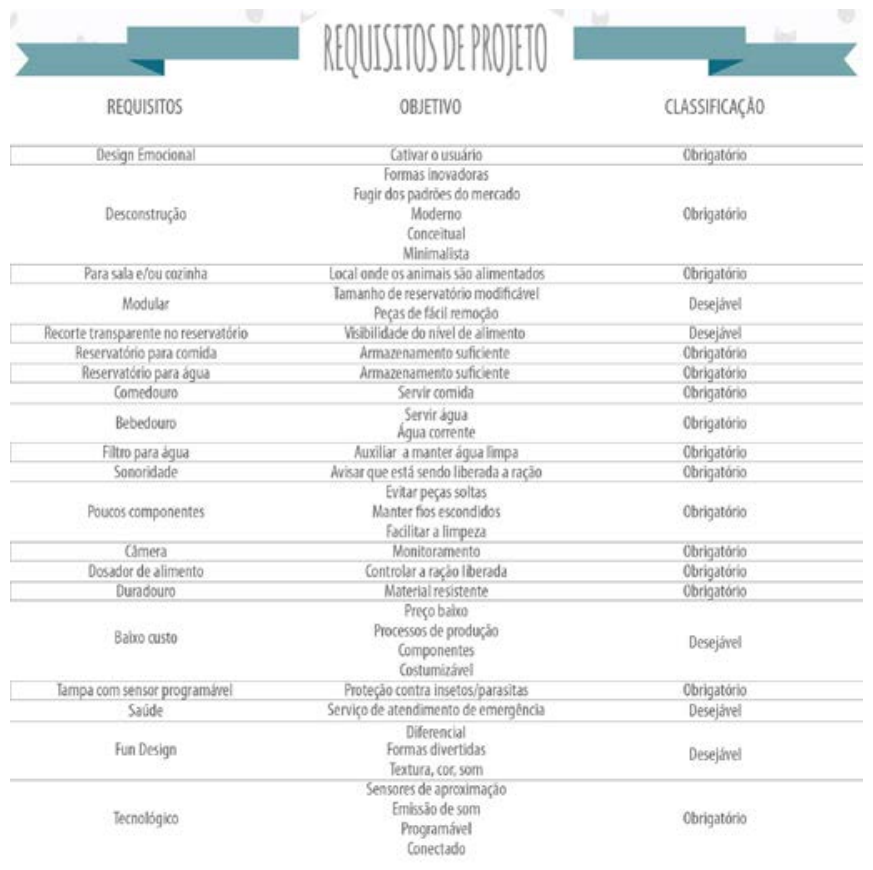

Quadro 2 Requisitos de Projeto

Fonte: Cândido et al. (2015)

A partir dos requisitos foram geradas alternativas e selecionada a melhor solução. Foram feitos os testes com o Arduíno para programar junto com o motor para a liberação da ração. Foram realizados testes com a bomba de água. 


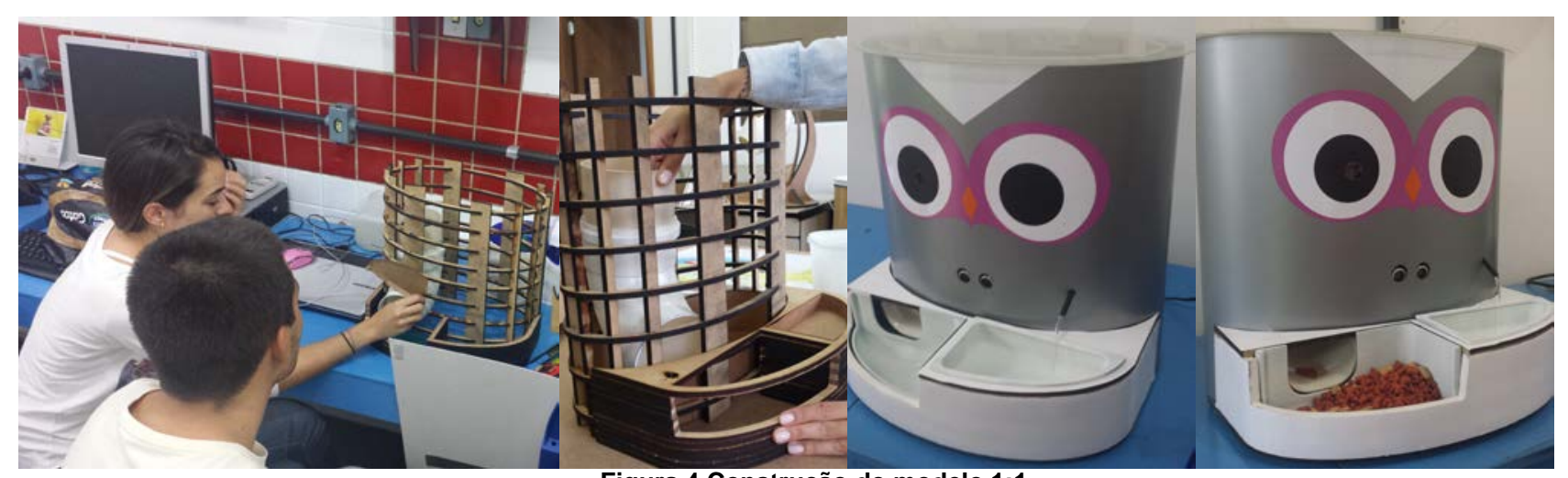

Figura 4 Construção do modelo 1:1

Fonte: Cândido et al. (2015)

O Alimentador Pet oferece a ludicidade do Fun Design, buscando elevar a relação entre Usuário X Produto. Possui em sua forma características visuais simbólicas, fazendo alusão a um animal, o que agrega personalidade ao produto. Também propõe uma alternativa de interatividade por meio da internet das coisas, a fim de alinhar forma e função em um produto para auxiliar, à distância, os cuidados dos animais de estimação.

A figura 5 mostra o detalhe estrutural do produto.

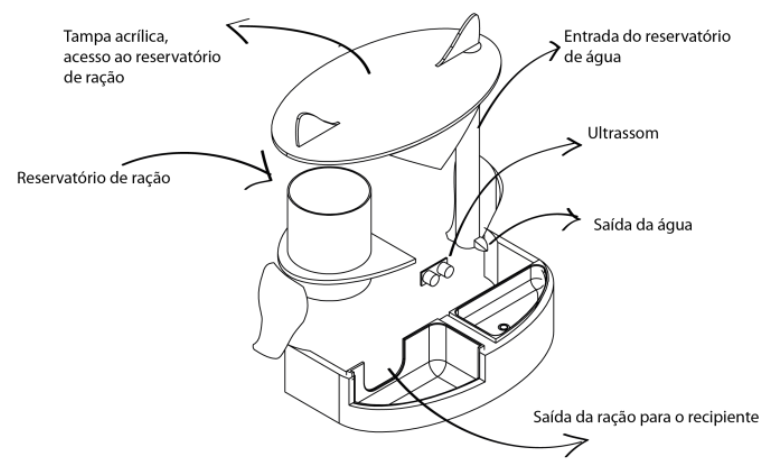

Figura 5 Detalhe estrutural do Alimentador Pet Fonte: Cândido et al. (2015)

E a figura 6 mostra a proposta do aplicativo para o produto ter conexão com a internet facilitando a interação do dono do animal.

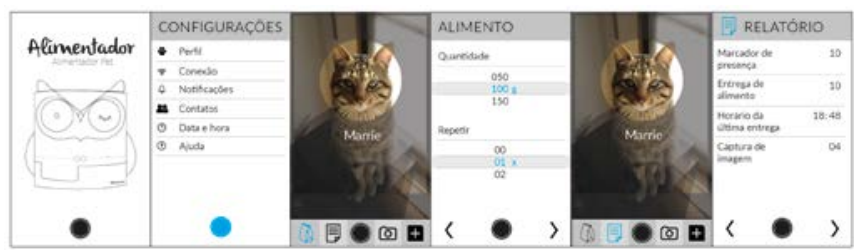

Figura 6 Telas do aplicativo do produto Fonte: Cândido et al. (2015)
Todas as características foram perfeitamente alinhadas à parte tecnológica do produto, que é composto por componentes eletrônicos, que permitem ao Alimentador Pet executar as funções pelas quais foi programado através de comandos, entrando no contexto da internet das coisas.

\section{Conclusões}

O modelo de gestão iterativo permite gerenciar de forma adequada a condução de um projeto de alta complexidade. No artigo foi mostrado um projeto realizado dentro de um módulo de projeto que tem um formato interdisciplinar de disciplinas de interação, materialização e inteligência. E apresentado o resultado da ação projetual.

O gerenciamento serve para cumprir e expor o método de trabalho, manter os professores envolvidos e a equipe de projeto organizada.

A organização similar a utilizada no mercado de trabalho permite que o aluno perceba a importância de trabalhar com os processos de materialização, programação, compra de componentes e testes. De forma a obter resultados dentro do prazo previamente estabelecido.

O processo de projetos de alta complexidade exige o trabalho de diversas áreas de saber isto exige uma nova linguagem descritiva e novas relações estruturais das disciplinas envolvidas na ação interdisciplinar e na busca da transdisciplinaridade que envolve o reconhecimento da interdependência dos saberes diversos. O ensino de projeto precisa atuar de forma profissional para preparar da melhor forma o futuro designer.

\section{Referencias}

CÂNDIDO, Kariny; CARDOSO, Gabriel; ROMA, Alice. (2015). Relatório de projeto: design inteligente para a criação de um produto para animais de estimação. Universidade Federal de Santa Catarina. Florianópolis, Brasil.

KERZNER, H. (2002). Gestão de Projetos: as melhores práticas. Porto Alegre: Bookman. 
PAZMINO, Ana; PUPO, Regiane; BRAGA, Rodrigo. (2014). Prática interdisciplinar em disciplina de projeto de produto com ênfase na inovação e na tecnologia. SIGRADI.

PROJECT MANAGEMENT INSTITUTE. (2004). A guide to the project management body of knowledge. (PMBOK Guide) Ed. PMI.
ROZENFELD, Henrique. et al. (2006). Gestão de desenvolvimento de produtos: Uma referência para a melhoria do processo. São Paulo: Saraiva. 